
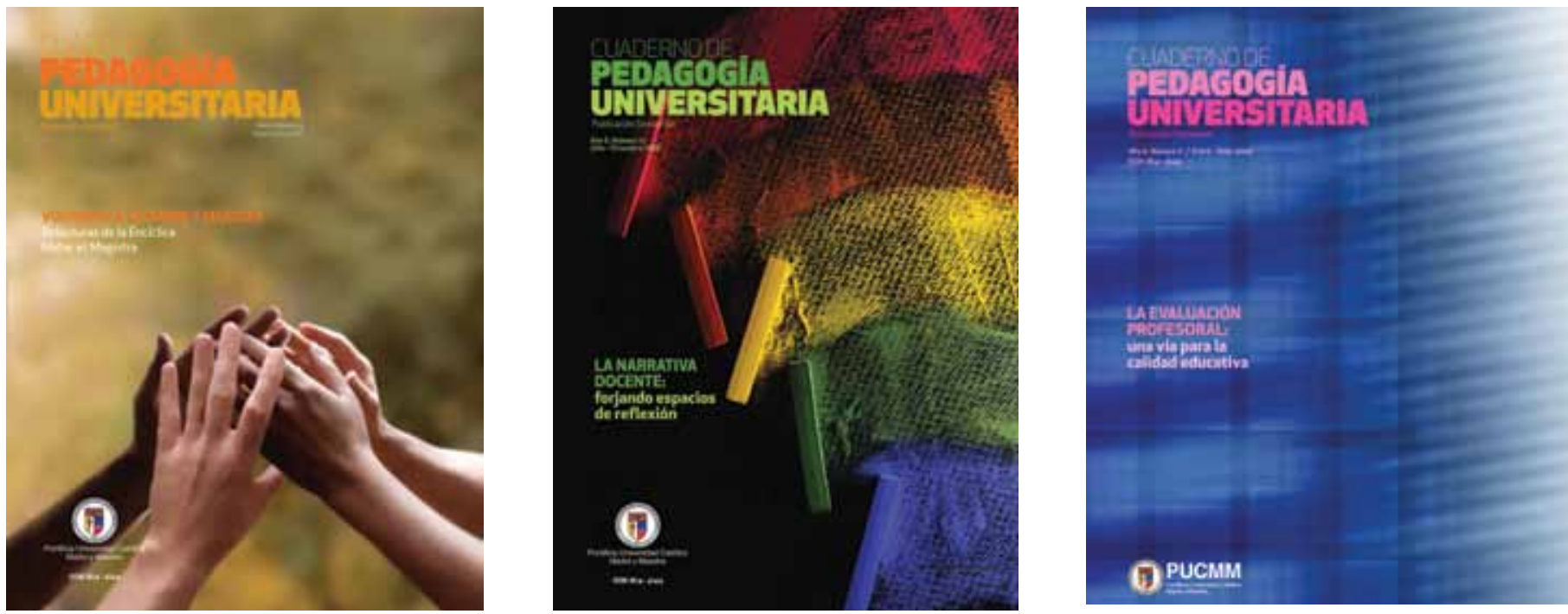

\title{
VOCES DE NUESTROS LECTORES
}

En esta sección publicamos opiniones que nos envian los lectores sobre los artículos del último ejemplar del Cuaderno de PedagogíaUniversitaria: “Los Estudios Generales en el currículum universitario", No. 14, julio-diciembre 2010

Quisiera referirme al último número del Cuaderno de Pedagogía Universitaria, que aborda el tema de los Estudios Generales, uno de los puntos más arduos y controvertidos del quehacer académico. El asunto, importante y valioso en sí mismo, llega en un momento particularmente oportuno. En efecto, como nos recuerdan las profesoras Taveras y Olivo, "la PUCMM ha iniciado un proceso de revisión, reflexión y reforma del Ciclo Básico", y "aún después que se implemente [la reforma] sabemos que esto será una espiral".

Muy certero, por tanto, haber incluido en la sección Ventanas Abiertas ponencias y exposiciones presentadas en eventos relacionados con el proceso en curso. Los artículos de esta sección, y los de las demás, nos hablan de experiencias de aquí y de allá sobre organización de los Estudios Generales. Se aportan fundamentaciones teóricas, se describen desarrollos históricos, se destacan perfiles deseables y se definen tareas pendientes. En fin, los materiales recogidos pueden leerse como argumentos favorables a la idea de que "los programas de Educación General considerados sólidos y eficientes no surgen por casualidad", por decirlo con palabras que aduce la profesora Haché de Yunén en Notas Bibliográficas. En cuanto a la identificación de una problemática sectorial y a las iniciativas tomadas para resolverla, encuentro ejemplar la contribución del profesor Tallaj a propósito de la enseñanza de las ciencias.

Termino felicitando a la Dirección y al personal del CDP por el mantenimiento de la Peña Pedagógica, cita semestral que contribuye a profundizar en el mensaje de las páginas del Cuaderno.

Ricardo Miniño, Departamento de Humanidades, PUCMM, Campus de Santiago

Lo planteado por los autores en el último ejemplar resalta la concepción humanista que intentamos promover en las aulas de la PUCMM. Me llamó la atención el artículo de Vélez y Subirats, en cuanto al papel del profesional docente y los elementos del perfil. Este artículo nos invita a reflexionar sobre nuestro rol como gestores de la calidad de la educación, revalorando cada día más al ser humano que tenemos como público objetivo: nuestros estudiantes.

Jeanette Chaljub, Departamento de Educación, Recinto Santo Tomás de Aquino, Santo Domingo 

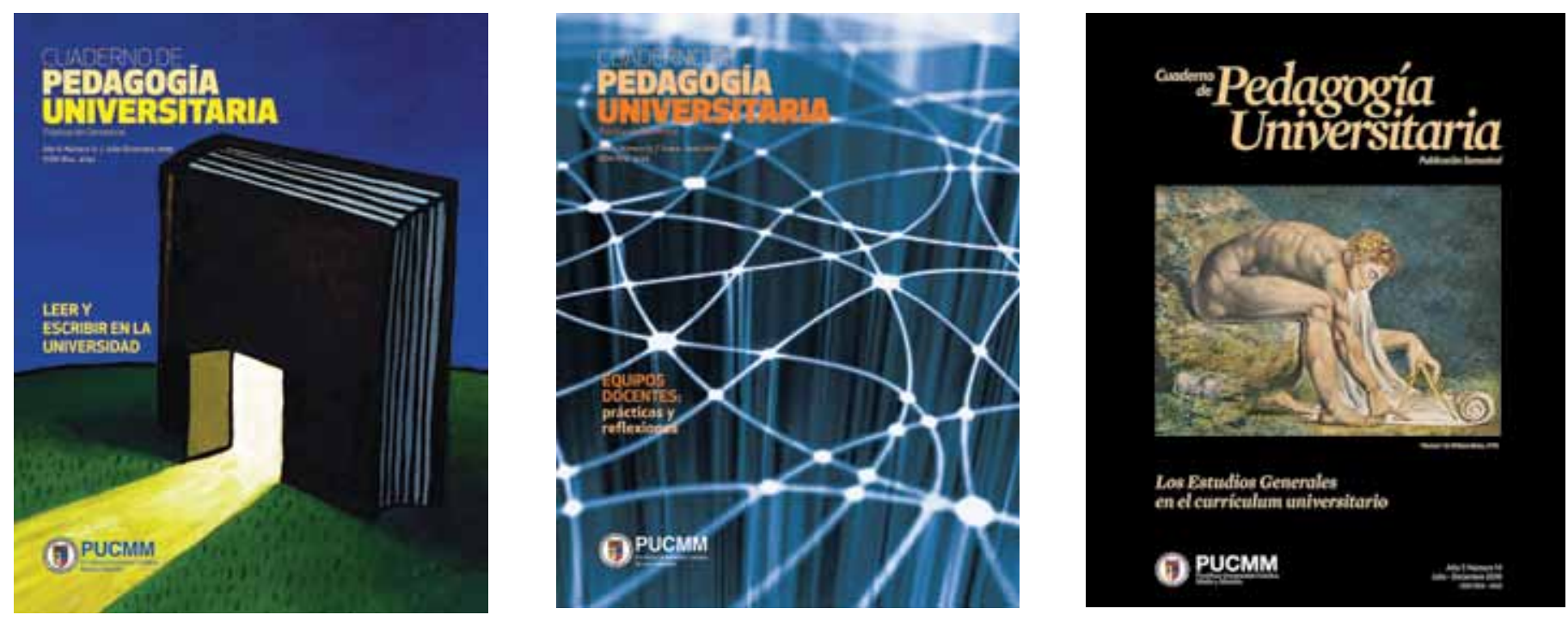

La disección practicada a los Estudios Generales universitarios, tema del último número del Cuaderno de Pedagogía Universitaria que recoge las ponencias del II Simposio de Estudios Generales realizado en 2010, constituye un aporte fundamental y oportuno para la socialización y enriquecimiento de las bases conceptuales de este importante aspecto del desarrollo curricular.

El componente de los Estudios Generales en el currículo se desprende de la concepción filosófica de la formación universitaria, la cual está íntimamente vinculada con la misión de la universidad. Me parecen particularmente certeros los conceptos emitidos por el Dr. Tubino al postular que en los Estudios Generales es importante acentuar "el peso curricular de la formación integral, ya que es una etapa de la vida en la que se necesita afinar la sensibilidad, la imaginación y el intelecto...". Estas consideraciones, al igual a las externadas por los demás autores en el citado número y, en especial, por la Lic. Ojeda, contribuyen a la consolidación de una formación holística que "hará bien la cabeza, en lugar de llenarla".

Fernando Arturo Russell, Departamento de Ciencias Básicas, PUCMM, Campus de Santiago

Estimados compañeros del Centro de Desarrollo Profesoral:

A través de la lectura del número anterior del Cuaderno de Pedagogía Universitaria, dedicado a los Estudios Generales (EG), pude apreciar la importancia que está otorgando nuestra universidad a este tema y su implicación en la redefinición del Ciclo Básico. Si bien los ponentes internacionales ampliaron nuestra visión sobre el tópico, también nos dejaron ver que los EG son parte de un modelo en constante cambio y reajuste a su contexto.

Es por eso que una importante aportación a la reflexión lo constituye el artículo del Ing. Marino Grullón, quien hace un recorrido histórico y analiza las diferentes interpretaciones que se han hecho al Ciclo Básico en nuestra Universidad, punto que no podemos dejar de considerar si queremos implementar exitosamente esta concepción.

A modo de opinión, recordando mis propias experiencias universitarias relativas a los EG, que dejaron una marca en mí, puedo decir que más que una modificación curricular, el concepto involucra un conjunto de vivencias en distintas asignaturas bien engarzadas entre sí para llevar a los estudiantes a la reflexión sobre su ser y su entorno. Si pudiera decirlo en pocas palabras, es una especie de "retiro espiritual e intelectual continuo" que muchas veces deja huellas más profundas en nuestra vida que el devenir cotidiano de exámenes y tareas. Pero esta experiencia, para poder transmitirla, es necesario haberla vivido antes, por lo que pienso que el primer paso es brindar a los profesores dicha vivencia tomando los modelos de otras latitudes y adaptándolos según los principios que tan claramente definen a nuestra Madre y Maestra.

\section{Antonio Rivero, Departamento Ciencias Básicas, Campus de Santiago}

